\title{
Article
}

\section{Biophysical investigation into the antibacterial action of modelin-5-NH2}

Dennison, Sarah Rachel, Hauß, Thomas, Harris, frederick, Phoenix, David Andrew and Badiani, Kamal

Available at http://clok.uclan.ac.uk/28433/

Dennison, Sarah Rachel ORCID: 0000-0003-4863-9607, Hauß, Thomas, Harris, frederick, Phoenix, David Andrew and Badiani, Kamal (2019) Biophysical investigation into the antibacterial action of modelin-5-NH2. Soft Matter, 15 (20). pp. 4215-4226. ISSN 1744-683X

It is advisable to refer to the publisher's version if you intend to cite from the work. http://dx.doi.org/10.1039/C8SM02374C

For more information about UCLan's research in this area go to http://www.uclan.ac.uk/researchgroups/ and search for <name of research Group>.

For information about Research generally at UCLan please go to http://www.uclan.ac.uk/research/

All outputs in CLoK are protected by Intellectual Property Rights law, including Copyright law. Copyright, IPR and Moral Rights for the works on this site are retained by the individual authors and/or other copyright owners. Terms and conditions for use of this material are defined in the policies page.

\section{CLoK}

Central Lancashire online Knowledge www.clok.uclan.ac.uk

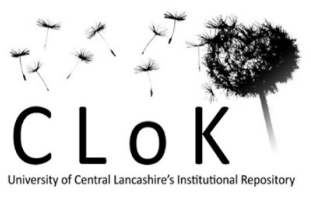


Citation: S. Dennison, T. Hauß, K. Badiani, F. Harris and D. A. Phoenix, Soft Matter, 2019, DOI: $10.1039 / C 8 S M 02374 C$.

\section{Biophysical investigation into the antibacterial action of modelin-5- $\mathrm{NH}_{2}$}

Sarah R. Dennison ${ }^{\mathrm{a}}$, Thomas Hau $\beta^{\mathrm{b}}$, Kamal Badiani ${ }^{\mathrm{c}}$, Frederick Harris ${ }^{\mathrm{d}}$ and David A. Phoenix ${ }^{\mathrm{e}^{*}}$

a. School of Pharmacy and Biological Sciences, University of Central Lancashire, Preston PR1 2HE, UK

b. Macromolecular Crystallography, Helmholtz-Zentrum Berlin für Materialien und Energie, Berlin, Germany

c. Pepceuticals Limited, 4 Feldspar Close, Warrens Park, Enderby, Leicestershire, LE19 4JS, UK;

d. School of Forensic and Investigative Science, University of Central Lancashire Preston PR1 2HE, UK;

e. Office of the Vice Chancellor, London South Bank University, 103 Borough Road, London SE1 OAA, UK E-mail address: phoenixd@lsbu.ac.uk* 


\begin{abstract}
Modelin-5- $\mathrm{CONH}_{2}\left(\mathrm{M} 5-\mathrm{NH}_{2}\right)$ is a synthetic antimicrobial peptide, which was found to show potent activity against Bacillus subtilis (Minimum lethal concentration $=8.47 \mu \mathrm{M}$ ) and to bind strongly to membranes of the organism $\left(\mathrm{K}_{\mathrm{d}}=10.44 \mu \mathrm{M}\right)$. The peptide adopted high levels of amphiphilic $\alpha$-helical structure in the presence of these membranes (> $50 \%$ ), which led to high levels of insertion $\left(\Delta \pi \geq 8.0 \mathrm{mN} \mathrm{m}^{-1}\right)$. M5- $\mathrm{NH}_{2}$ showed high affinity for anionic lipid $\left(\mathrm{K}_{\mathrm{d}}=7.46\right.$ $\mu \mathrm{M})$ and zwitterionic lipid $\left(\mathrm{K}_{\mathrm{d}}=14.7 \mu \mathrm{M}\right)$, which drove insertion into membranes formed from these lipids ( $\Delta \pi=11.5$ and $3.5 \mathrm{mN} \mathrm{m}^{-1}$, respectively). Neutron diffraction studies showed that M5$\mathrm{NH}_{2}$ inserted into $B$. subtilis membranes with its $\mathrm{N}$-terminal residue, L16, located $5.5 \AA$ from the membrane centre, in the acyl chain region of these membranes, and promoted a reduction in membrane thickness of circa $1.8 \AA$ or $5 \%$ of membrane width. Insertion into B. subtilis membranes by the peptide also promoted other effects associated with membrane thinning, including increases in membrane surface area $\left(\mathrm{C}_{\mathrm{s}}^{-1}\right.$ decreases) and fluidity $\left(\Delta \mathrm{G}_{\operatorname{mix}}>0\right.$ to $\Delta \mathrm{G}_{\operatorname{mix}}<$ 0 ). Membrane insertion and thinning by $\mathrm{M} 5-\mathrm{NH}_{2}$ induced high levels of lysis $(>55 \%)$, and it is speculated that the antibacterial action of the peptide may involve the toroidal pore, carpet or tiltedtype mechanism of membrane permeabilization.
\end{abstract}




\section{Introduction}

The emergence of microbial pathogens with multiple drug resistance (MDR) has rendered bacterial infections as one of the leading global causes of mortality, precipitating a serious public health issue in countries across the world ${ }^{1}$. Due to the gravity of the threat posed by MDR pathogens, the World Health Organization (WHO) has ranked MDR as a priority issue, which if not remedied, could usher a return to the pre-antibiotic era when many common diseases were untreatable ${ }^{2}$. More recently, major reports by the WHO and the UK Government have called for harmonized, global action to counter the threat posed by MDR pathogens, which includes the identification of new antibiotics and the development of novel antimicrobial strategies ${ }^{3,4}$. Most recently, the WHO took the unprecedented step of publishing a list of the twelve MDR bacteria that pose the greatest threat to human health with the aim of catalysing the development of crucially needed, new antibiotics to kill these 'priority pathogens' 5 . For example, Acinetobacter baumannii is listed and whilst in the early 1970s, the organism was largely unknown and recognized as an opportunistic, nosocomial pathogen, primarily infecting critically ill or immunocompromised patients it was susceptible to most antibiotics. By the 1990s, it was increasingly becoming established as an emergent, opportunistic pathogen with $\mathrm{MDR}^{6}$ and today, this organism has acquired resistance to virtually all antibiotics capable of treating Gram-negative bacteria, including carbapenems, which are 'last-line' $\beta$-lactams used to treat infections caused by these organisms ${ }^{7}$. More recently, strains of carbapenem-resistant A. baumannii have emerged with resistance to colistin, which, due to its neurotoxicity and nephrotoxicity, was considered to be the 'last resort' drug capable of treating infections caused by the organism 8. Currently, carbapenem-resistant $A$. baumannii is regarded as the most difficult nosocomial pathogen to treat, which is reflected by its 'critical' priority and position at the top of the 'priority pathogens' list ${ }^{5}$.

The call by the WHO and UK Governments for global action to combat the threat of MDR pathogens proposes a number of interventions and a major example is the therapeutic

development of antimicrobial peptides (AMPs) ${ }^{3,4}$. These peptides are endogenous antimicrobials that have been identified in living things across the eukaryotic kingdom and 
have potent activity against not only bacteria, but also viruses, fungi, parasites and even cancer cells ${ }^{9-12}$. A variety of resistance mechanisms to AMPs have been described in bacteria, which generally involve the inherent properties of these organisms rather than the acquisition of dedicated resistance genes ${ }^{13}$. This intrinsic protection from AMPs is generally moderate in level and relatively non-specific in nature, which is reflected in the low frequency of resistant bacteria and the evolutionary persistence and success of these peptides ${ }^{14}$. The evolution of bacterial resistance to AMPs has been demonstrated experimentally ${ }^{15}$, but based on the pharmacodynamics of these peptides, it has been predicted that they are much less likely to select for resistant mutants in vivo than conventional antibiotics ${ }^{16}$. Indeed, recent studies have suggested that the likelihood of bacteria developing resistance to AMPs is greatly reduced when they are exposed to synergistic combinations of these peptides, as would be the case in vivo ${ }^{17}$. These observations have led to the generally held view that bacterial resistance to AMPs is unlikely to approach the levels observed for conventional antibiotics ${ }^{9,10}$, although this view has been questioned ${ }^{15}$. Other advantages of AMPs include high potency and selectivity, a broad range of targets, potentially low toxicity and low accumulation in tissues. These are highly desirable properties in the development of therapeutically useful antimicrobial agents ${ }^{18}$. However, the full commercial exploitation of AMPs has been hindered for a variety of reasons, primarily their high cost of manufacture and their strong tendency to undergo proteolytic degradation in vivo ${ }^{10,12}$. In response, concerted attempts to develop AMPs by producing analogues, mimics, and de novo, synthetic forms of these peptides have been undertaken and currently, a number of these molecules are in clinical trials and therapeutic use ${ }^{9,10,12}$.

A synthetic AMP with many of the properties needed for therapeutic development is modelin-5-CONH $2\left(\mathrm{M} 5-\mathrm{NH}_{2}\right)$, which is an $\alpha$-helical peptide with anticancer activity ${ }^{19-21}$ and broad range antimicrobial action ${ }^{20,22-25}$ that is accompanied by negligible lysis of erythrocytes from humans and other mammals ${ }^{26}$. The peptide is effective against a variety of Gram-negative bacteria, including clinical isolates ${ }^{22}$, and its ability to kill the archetypical member of these organisms, Escherichia coli, has been well characterised, appearing to involve a carpet-type mechanism ${ }^{24,25}$. M5- $\mathrm{NH}_{2}$ also possesses activity against 
Gram-positive bacteria 22, 23, Bacillus subtilis, which is generally taken as the model organism for this bacterial class and which forms the focus of the present study ${ }^{27}$. The peptide was found to possess potent activity against this organism and a range of biophysical techniques, including neutron diffraction, lipid monolayers and CD spectroscopy, are used to investigate the antibacterial mechanism involved. This mechanism appears to involve the ability of anionic lipid in B. subtilis membranes to promote the adoption of high levels of amphiphilic $\alpha$-helical structure by $\mathrm{M}^{2}-\mathrm{NH}_{2}$. This amphiphilic secondary structure then appears to drive the penetration, thinning and lysis of the organism's membranes by the peptide. It is speculated that this lysis involves one of the following mechanisms of action: toroidal pore, carpet and tilted-type. 


\section{Experimental}

Materials

$\mathrm{M}-\mathrm{NH}_{2} \quad\left(\mathrm{KLAKKLAKLAKLAKAL-CONH}_{2}\right)$ and d-M5-NH2-L16 (KLAKKLAKLAKLAKAL(d16)-CONH 2 ) were supplied by Pepceuticals (Leicestershire, UK), and were purified by HPLC to purity greater than $95 \%$, confirmed by MALDI mass spectrometry. All buffers were prepared using ultra-pure water (resistivity $18 \mathrm{M} \Omega \mathrm{cm}$ ). The phospholipids 1-palmitoyl-2-oleoyl-sn-glycero-3-phosphoglycerol (POPG) and 1palmitoyl-2-oleoyl-sn-glycero-3-phosphoethanolamine (POPE) were purchased from Avanti Polar Lipids (Alabaster, AL). Ringer's solution (RS), Nutrient broth (NB) and Nutrient agar (NA) were purchased from Thermo Fisher Scientific (Leicestershire, UK). HPLC grade solvents were obtained from VWR International Ltd (Lutterworth, UK) and all other regents were purchased from Sigma-Aldrich Company Ltd. (Dorset, UK).

\section{Methods}

The theoretical analysis of $\mathbf{M 5}-\mathbf{N H}_{2}$. The sequence of $\mathrm{M} 5-\mathrm{NH}_{2}$ was modelled as a twodimensional axial projection assuming an angular periodicity of $100^{\circ}$ according to the helical wheel analysis of Schiffer and Edmundson ${ }^{28}$. The amphiphilicity of this $\alpha$-helical arrangement was quantified as $\langle\mu \mathrm{H}\rangle$, according to hydrophobic moment methodology using a moving window of eleven residues and the normalized consensus hydrophobicity scale of Eisenberg ${ }^{29}$. The potential of $\mathrm{M}^{2}-\mathrm{NH}_{2}$ to form a tilted peptide was investigated by amphiphilic profiling using $-\langle\mu \mathrm{H}\rangle$, with a moving window of seven residues and the normalized consensus hydrophobicity scale of Eisenberg ${ }^{30}$.

The antibacterial activity of $\mathbf{M 5}-\mathrm{NH}_{2}$. The antibacterial activity of $\mathrm{M} 5-\mathrm{NH}_{2}$ was determined using B. subtilis (strain NCIMB 1671), which was taken from a frozen stock ($80{ }^{\circ} \mathrm{C}$ ), inoculated into $10 \mathrm{ml}$ aliquots of sterile $\mathrm{NB}$ and incubated in an orbital shaker (100 $\mathrm{rpm}$ and $\left.37^{\circ} \mathrm{C}\right)$ until the exponential phase $(\mathrm{OD}=0.6 ; \lambda=600 \mathrm{~nm})$ was reached. This culture was then centrifuged at $15000 \times \mathrm{g}$ and $4{ }^{\circ} \mathrm{C}$ for $10 \mathrm{~min}$ using a bench top centrifuge and the resultant cell pellet washed 3 times in $1 \mathrm{ml}$ aliquots of $25 \%$ strength $\mathrm{RS}$, before being resuspended in $1 \mathrm{ml}$ of $25 \%$ strength $\mathrm{RS}$. For the standard assay, these samples were 
further diluted with $25 \%$ strength RS to achieve a bacterial density of $106 \mathrm{CFU} \mathrm{ml}^{-1}$. Then, $10 \mu \mathrm{l}$ aliquots of these cell suspensions were taken, inoculated with $1 \mathrm{ml}$ of $\mathrm{M} 5-\mathrm{NH}_{2}$ in $\mathrm{RS}$ to give final peptide concentrations of $3.90 \mu \mathrm{M}$ to $1 \mathrm{M}$ and incubated overnight at $37{ }^{\circ} \mathrm{C}$. As a control, cultures of $B$. subtilis were similarly treated but in the absence of $\mathrm{M} 5-\mathrm{NH}_{2}$. After incubation, $10 \mu \mathrm{l}$ aliquots of the control samples and bacterial cultures that had been treated with M5- $\mathrm{NH}_{2}$ were surface spread onto an NA plate and incubated at $37{ }^{\circ} \mathrm{C}$ for 12 hours. After incubation, the plates were viewed and the lowest peptide concentration yielding no bacterial growth was identified as the minimal lethal concentration (MLC) of M5-NH2. These experiments were repeated 4 times and the average MLCs determined ${ }^{25}$.

The conformational analysis of $\mathrm{M5}-\mathrm{NH}_{2}$. The conformational preferences of $\mathrm{M} 5-\mathrm{NH}_{2}$ in the presence of small unilamellar vesicles (SUVs), formed from POPE, POPG, or lipid mixtures, were analysed using a J-815 spectropolarimeter (Jasco, UK) at $20{ }^{\circ} \mathrm{C}$ with the vesicles acting as model B. subtilis membranes. These SUVs acting as model B. subtilis membranes were formed from mixtures of POPG and POPE in the molar ratio 70:30 or total lipid extracts of the organism's membranes, which were dissolved in chloroform. These various lipid solutions were then dried under $\mathrm{N}_{2}$ gas, vacuum-dried for 4 hours, and the resulting lipid films rehydrated using $1 \times \mathrm{PBS}(\mathrm{pH} 7.5)$. Rehydrated samples were then vortexed for $5 \mathrm{~min}$ and the resulting lipid suspensions sonicated for $30 \mathrm{~min}$ using a Soniprep 150 (ISTCP, USA) sonicator until clear, followed by three cycles of freeze-thawing. The resulting solutions of SUVs were then extruded 11 times through a $0.1 \mu$ m polycarbonate filter using an Avanti (UK) polar lipids mini-extruder apparatus and diluted 10-fold using $1 \times$ PBS $(\mathrm{pH} 7.5)$. These diluted SUVs were then mixed with stock M5- $\mathrm{NH}_{2}$ solution (final concentration of $0.1 \mathrm{mg} \mathrm{ml}-1$ ) to give samples with a peptide:lipid molar ratio of 1:100. Both in the presence and absence of these SUVs, far-UV CD spectra were collected for M5- $\mathrm{NH}_{2}$, where four scans per sample were obtained using a $10 \mathrm{~mm}$ path-length cell. Each scan was performed over a wavelength range of 260 to $180 \mathrm{~nm}$ at $0.5 \mathrm{~nm}$ intervals employing a bandwidth of $1 \mathrm{~nm}$ and at a speed $50 \mathrm{~nm} \mathrm{~min}{ }^{-1} 31$. For all spectra acquired, the baseline acquired in the absence of peptide was subtracted and the percentage $\alpha$-helical content of M5-NH2 estimated using the CDSSTR method (protein reference set 3) from the 
DichroWeb server ${ }^{32}$. These experiments were repeated 4 times and the percentage $\alpha$ helicity was averaged.

The interaction of $\mathrm{M5}-\mathrm{NH}_{2}$ with lipid monolayers. Insertion experiments were carried out at constant area to quantify the interaction of $\mathrm{M} 5-\mathrm{NH}_{2}$ with lipid monolayers using a $601 \mathrm{M}$ Langmuir trough (Biolin ScientificlKSV NIMA, Coventry, UK). Chloroformic lipid solutions (1 mg ml $\mathrm{m}^{-1}$ ), which contained POPE, POPG, mixtures of POPG and POPE in the molar ratio 70:30 or lipid extracts from membranes of B. subtilis, were spread drop-wise onto an air-buffer $(1 \times$ PBS, pH 7.4) interface using a Hamilton syringe. The solvent was allowed to evaporate and, then, monolayers were compressed by 2 moveable Derlin barriers with a velocity of $50 \mathrm{~mm} \mathrm{~min}^{-1}$ to a starting surface pressure of $30 \mathrm{mN} \mathrm{m}-1$, which corresponds to that generated by the packing density of naturally occurring cell membranes ${ }^{33}$. Once the monolayer was stable at a starting pressure of $30 \mathrm{mN} \mathrm{m}^{-1}, \mathrm{M} 5-\mathrm{NH}_{2}$ was injected underneath the monolayer to give a final peptide concentration of $6 \mu \mathrm{M}$ in the subphase (1 $\times$ PBS pH 7.4). The surface area of monolayers was kept constant via a built-in controlled feedback system, and surface pressure increases were monitored by the Wilhelmy method using a Whatman's $\mathrm{CH} 1$ filter paper plate and microbalance ${ }^{31}$. All experiments were carried out at $20^{\circ} \mathrm{C}$ and repeated 4 times.

Thermodynamic analysis $\mathrm{M5}-\mathrm{NH}_{2}$ with lipid monolayers. Compression isotherms were generated from monolayers formed from POPG and POPE in the molar ratio 70:30. Chloroformic solutions of these lipid molecules $\left(2.5 \times 10^{15}\right)$ were spread onto a buffer subphase $(1 \times \mathrm{PBS}, \mathrm{pH} 7.4)$, the solvent allowed to evaporate for $10 \mathrm{~min}$ and the monolayer left to stabilize for a further $20 \mathrm{~min}$. The trough barriers were then closed at a speed of 0.22 $\mathrm{nm}^{2} \mathrm{~min}^{-1}$ until monolayer collapse pressure was achieved. Surface pressure changes were monitored and plotted as a function of the area per lipid molecule. Corresponding experiments were then performed except that $\mathrm{M} 5-\mathrm{NH}_{2}$ was introduced into the subphase to give a final peptide concentration of $6.0 \mu \mathrm{M}$. All experiments were carried out at $20^{\circ} \mathrm{C}$ and repeated 4 times ${ }^{31}$.

Thermodynamic analysis of these isotherms was undertaken and compressibility moduli $\left(\mathrm{C}^{-1}\right)$ determined to provide a measurement of the compressional elasticity of monolayers 
and hence information about the packing of their component molecules. $\mathrm{Cs}_{\mathrm{s}}^{-1}$ was computed according to equation 1 [39]:

$$
\mathrm{C}_{\mathrm{s}}^{-1}=-\boldsymbol{A}\left(\frac{\delta \pi}{\delta \boldsymbol{A}}\right)
$$

where $\pi$ is surface pressure of the monolayer and A represents the area per lipid molecule in the monolayer.

Thermodynamic analysis of these isotherms was also used to determine the Gibbs free energy of mixing $\left(\Delta \mathrm{G}_{m i x}\right)$ of monolayers, which provides a measure of the relative stability associated with the miscibility energetics of their pure lipid components. Thermodynamically stable and thermodynamically unstable monolayers are indicated by negative and positive values of $\Delta \mathrm{G}_{\text {mix }}$ respectively ${ }^{33} . \Delta \mathrm{G}_{\text {mix }}$ was computed according to equation 2:

$$
\Delta G_{m i x}=\int\left[A_{1,2}-\left(X_{1} A_{1}+X_{2} A_{2}\right)\right] d \pi
$$

where $A_{1,2}$, is the molecular area occupied by the mixed monolayer, $A_{1}, A_{2}$ are the area per lipid molecule in the pure monolayers of component 1 and $2, \mathrm{X}_{1}, \mathrm{X}_{2}$ are the molar fractions of the components and $\pi$ is the surface pressure. Numerical data were calculated from the compression isotherms according to the mathematical method of Simpson ${ }^{34}$.

The membranolytic ability of M5- $\mathbf{N H}_{2}$. The membranolytic ability $\mathrm{M} 5-\mathrm{NH}_{2}$ was determined using a dye release assay ${ }^{25}$. Chloroformic solutions of lipid $\left(7.5 \mathrm{mg} \mathrm{ml}^{-1}\right)$ in the form of either, POPG and POPE in the molar ratio 70:30 or total lipid extracts from membranes of $B$. subtilis. These solutions were dried under $\mathrm{N}_{2}$ gas and kept under vacuum for at least 12 hours to ensure complete removal of the solvent. The resulting lipid films were then hydrated with $1 \mathrm{ml}$ of 5.0 M 4-(2-hydroxyethyl)-1-piperazineethanesulfonic acid (HEPES) ( $\mathrm{pH} \mathrm{7.5)} \mathrm{containing} \mathrm{calcein}(70.0 \mathrm{mM})$ and the suspension vortexed for $5 \mathrm{~min}$ before being sonicated for $30 \mathrm{~min}$, which was followed by 3 cycles of freeze-thawing to maximize calcein encapsulation. Vesicular encapsulated calcein was then separated from the free dye by elution with HEPES (5.0 mM, pH 7.5) down a Sephadex G75 column (SIGMA, UK), which had been rehydrated overnight in HEPES (20.0 mM, pH 7.5), NaCl $(150 \mathrm{mM})$ and Ethylenediaminetetraacetic acid (EDTA, $1.0 \mathrm{mM})$. The calcein release assay was performed by combining $25 \mu \mathrm{L}$ of vesicular encapsulated calcein with $50 \mu \mathrm{L}$ of $10 \mu \mathrm{M}$ 
M5- $\mathrm{NH}_{2}$, which was then made up to a final volume of $1 \mathrm{ml}$ with 20.0 mM HEPES, 150.0 $\mathrm{mM} \mathrm{NaCl}$ and $1.0 \mathrm{mM}$ EDTA $(\mathrm{pH}$ 7.4). The fluorescence intensities of calcein was monitored at $20^{\circ} \mathrm{C}$ using an FP-6500 spectrofluorometer (JASCO, UK), with an excitation wavelength of $490 \mathrm{~nm}$ and emission wavelength of $520 \mathrm{~nm}$. The fluorescence intensity induced by the addition of $10 \mu \mathrm{L}$ of triton X-100 (10\%, v/v) to vesicular encapsulated calcein was taken to represent $100 \%$ dye release and was used to calculate the relative \% of calcein released from vesicles by $\mathrm{M} 5-\mathrm{NH}_{2}$. All experiments were repeated 4 times.

The membrane binding properties of $\mathbf{M 5}-\mathrm{NH}_{2}$. A fluorescent probe assay was used to evaluate the ability of $\mathrm{M} 5-\mathrm{NH}_{2}$ to bind to membranes ${ }^{25}$. SUVs formed from POPG and POPE in the molar ratio 70:30 were prepared and fluorescein-phosphatidylethanolamine (FPE, $0.5 \mathrm{M}$ ) was added to the organic solvent before drying under vacuum overnight to create a lipid film. These films were then hydrated with Tris- $\mathrm{HCl}(10.0 \mathrm{mM}, \mathrm{pH} 7.4)$ and EDTA $(1.0 \mathrm{mM})$, followed by freeze-thawing 5 times and extrusion 11 times through an Avanti mini-extruder apparatus containing a $0.1 \mu \mathrm{m}$ polycarbonate filter. Fluorescence was recorded using an FP-6500 spectrofluorometer (JASCO, UK), with an excitation wavelength of $492 \mathrm{~nm}$, an emission wavelength of $516 \mathrm{~nm}$, and excitation and emission slits set to $5 \mathrm{~nm}$. To investigate the binding of peptide to lipid vesicles, $\mathrm{M} 5-\mathrm{NH}_{2}$ in the range 0 to $325 \mu \mathrm{M}$, was added to the FPE-labelled SUVs and the fluorescence monitored. The change in fluorescence $(\Delta \mathrm{F})$ was then determined as the fluorescence of FPE-labelled vesicles in the presence of peptide minus that of FPE-labelled vesicles in the absence of peptide. These $\Delta \mathrm{F}$ values were then plotted against the concentration of $\mathrm{M} 5-\mathrm{NH}_{2}$ and then fitted by non-linear least squares analysis to equation 3 :

$$
\Delta \boldsymbol{F}=\Delta \boldsymbol{F}_{\text {Max }}[A] / \boldsymbol{K}_{d}+[\boldsymbol{A}]
$$

Where $[\mathrm{A}]$ is the concentration of $\mathrm{M} 5-\mathrm{NH}_{2}, \Delta \mathrm{F}$ is the change in fluorescence, $\Delta \mathrm{F}_{\text {Max }}$ is the maximum change in fluorescence and $\mathrm{K}_{\mathrm{d}}$, is the binding coefficient of the peptide. All experiments were repeated 4 times and the average value of $\Delta \mathrm{F}$ calculated.

Neutron diffraction localization of $\mathbf{M 5}-\mathrm{NH}_{2}$ in lipid bilayers. Neutron diffraction experiments to determine the disposition of $\mathrm{M} 5-\mathrm{NH}_{2}$ in lipid bilayers were carried out on the V1 neutron membrane diffractometer at BER II, Helmholtz-Zentrum für Materialien 
und Energie, Berlin ${ }^{35}$. Chloroformic solutions $\left(20 \mathrm{mg} \mathrm{ml}^{-1}\right)$ containing POPG and POPE in the molar ratio, 70:30 were prepared. Aliquots $(1 \mathrm{ml})$ of these lipid solutions, and these solutions containing either protonated $\mathrm{M} 5-\mathrm{NH}_{2}$ ( $3 \%$ molar), or this peptide deuterated at leucine 16 of its primary structure, d-M5- $\mathrm{NH}_{2}-\mathrm{L} 16$ (3\% molar), were individually deposited onto quartz microscope slides using an artist's airbrush. The slides were then placed in a vacuum desiccator for $12 \mathrm{~h}$ to remove all traces of chloroform before rehydration for $24 \mathrm{~h}$ at $25{ }^{\circ} \mathrm{C}$ with relative humidity maintained at $98 \%$ using Teflon water baths containing saturated potassium sulphate solution in $8 \%{ }^{2} \mathrm{H}_{2} \mathrm{O}$. The scanning procedure consisted of sequential $\theta$ scans around the predicted Bragg angle for each order. The rocking scans covered the Bragg position $\theta$ for the angle $\theta \pm 2^{\circ}$. Diffraction patterns of the prepared samples were measured with up to five orders detected for each sample. The raw data from the two dimensional detector were summed to intensity versus $2 \theta$ using the V1 instrumental software ${ }^{36}$. The commercial software IGOR Pro (version 4) was used for all further data analysis. The lamellar, or bilayer, spacing ' $d$ ' of each sample was calculated by least-square fitting of the observed $2 \theta$ values to equation 4 , the Bragg equation:

$$
\mathrm{N} \lambda=2 \mathrm{~d} \sin \theta
$$

where $\mathrm{N}$ is the diffraction order and $\lambda$ is the neutron wavelength (4.52 $\AA$ ). The integrated intensities were calculated based upon the Gaussian fit of the experimental Bragg reflections. Absorption correction and Lorentz factor were applied and their intensities square-rooted to produce structure-factor amplitudes. The phase assignment of each order and the relative scaling of the different data sets were determined by contrast variation in the aqueous atmosphere by adjusting the molar ${ }^{2} \mathrm{H}_{2} \mathrm{O} / \mathrm{H} 2 \mathrm{O}$ ratio to $8 \%, 20 \%$, and $50 \%$ ${ }^{2} \mathrm{H}_{2} \mathrm{O}{ }^{36}$. The scattering length density profiles $\rho(z)$ were then calculated for each sample using equation 5 :

$$
\rho(\mathrm{z})=\rho 0+2 / \mathrm{d} \sum f(\mathrm{~h}) \cos (2 \pi \mathrm{hz} / \mathrm{d})
$$

where $\rho 0(z)$ is the integral density per unit length of the bilayer, $f(h)$ are the scaled structure factors and the second term describes the distribution in the scattering lengths across the bilayer. 


\section{Results}

The theoretical analysis of $\mathrm{M5}-\mathrm{NH}_{2}$. The sequence of $\mathrm{M} 5-\mathrm{NH}_{2}$ was modelled as a twodimensional axial projection and the peptide displayed amphiphilicity with six lysine residues and the amide moieties on lysine 1 and leucine 16 generating positive charge on the hydrophilic face. (Fig. 1A) and suggesting a preference for binding to anionic membrane components ${ }^{37}$. The amphiphilicity was quantified by the hydrophobic moment, $<\mu \mathrm{H}>$, with a value of 0.75 , which is typical of peptides active at the membrane interface ${ }^{29}$ and consistent with an ability to partition into the membrane ${ }^{37}$.

A



B

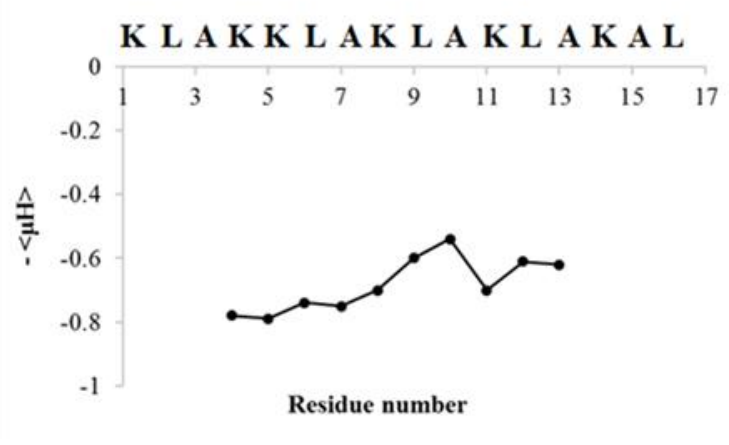

Fig. 1. Theoretical analysis of $\mathrm{M} 5-\mathrm{NH}_{2} \cdot \mathrm{M} 5-\mathrm{NH}_{2}$ displayed a cationic $\alpha$-helix, with a hydrophilic face rich in lysine residues and a hydrophobic face comprising alanine and leucine residues (Fig. 1A). The hydrophobic moment for this $\alpha$-helix was $\langle\mu H\rangle=0.75$, indicating strong amphiphilicity and the potential for high levels of activity at a membrane interface ${ }^{29} \cdot \mathrm{M}_{5}-\mathrm{NH}_{2}$ showed an amphiphilic profile with - $\langle\mu H\rangle$ generally increasing over residues 4 to 13 in the $\mathrm{N}$ $\rightarrow \mathrm{C}$ direction, indicating the potential for hydrophobicity gradient and tilted peptide formation. Values of $-<\mu H>$ increased from circa -0.8 to -0.6 , consistent with formation of a tilted peptide that occupies locations in the upper regions of the membrane (Fig. 1B) ${ }^{30}$. 
The potential of $\mathrm{M} 5-\mathrm{NH}_{2}$ to form a tilted peptide was investigated by amphiphilic profiling using $-<\mu H>$, which provides a graphical representation of the hydrophobicity gradients possessed by these peptides along their $\alpha$-helical long axis. This asymmetric distribution of hydrophobicity is predicted to cause the parent peptide to penetrate membranes at a shallow angle of between $20^{\circ}$ and $80^{\circ}$, thereby promoting a range of membrane destabilizing effects including the disturbance of lipid organisation and the compromise of bilayer integrity ${ }^{30,37} \cdot \mathrm{M} 5-\mathrm{NH}_{2}$ exhibited a hydrophobicity gradient with values of $-\langle\mu H\rangle$ that generally increased from circa -0.8 to -0.6 in the $\mathrm{N} \rightarrow \mathrm{C}$ direction and which extended over residues 4 to 13 (Fig. 1B). Values of $-\langle\mu H\rangle$ of this order are consistent with tilted penetration by the peptide into the surface regions of the membrane 30, 37. This contrasts to the tilted peptide, maximin H5, whose hydrophobicity gradient is characterised by much lower values of $-\langle\mu H\rangle$ than those of $\mathrm{M} 5-\mathrm{NH}_{2}$ and appears to promote deep penetration of the central core region of membranes 31,38 .

The antibacterial and membranolytic activity of $\mathbf{M 5}-\mathbf{N H}_{2}$. The antibacterial activity of M5- $\mathrm{NH}_{2}$ was evaluated against $B$. subtilis using a standard assay, and the peptide exhibited potent action against this organism with an MLC of $8.47 \mu \mathrm{M}$. This level of activity is circa 10 to 15 fold stronger than that generally shown by the peptide towards other bacteria, indicating that B. subtilis is highly susceptible to the action of $\mathrm{M} 5-\mathrm{NH}_{2}{ }^{19}, 20,22-25$. For all AMPs, antibacterial activity involves membrane interaction 9,10,12 and the calcein release assay is frequently used to probe the structure / function relationships involved in these interactions ${ }^{39}$. Use of this assay showed that $\mathrm{M} 5-\mathrm{NH}_{2}$ induced $59.3 \%$ leakage of the dye in vesicles formed from POPG and POPE in the molar ratio 70:30 and 56.77\% leakage in those formed from lipid extracts of membranes from B. subtilis. These levels of calcein release show that $\mathrm{M} 5-\mathrm{NH}_{2}$ is able to induce high levels of permeability in these membrane mimics and are typical of strongly membranolytic AMPs, as reported for the antibacterial and anticancer action of maximin $\mathrm{H} 5{ }^{31,38}$. Taken with the high level of toxicity shown by M5- $\mathrm{NH}_{2}$ towards $B$. subtilis, these calcein release data also illustrate the general tendency of AMPs to reflect potency in biological action as efficacy in membranolysis $9,10,12$. 
The conformational analysis of M5-NH2. CD spectroscopy is commonly used to study conformational changes in AMPs, a primary determinant in their antimicrobial action ${ }^{40}$. Use of this technique showed that for all SUVs studied, $\mathrm{M} 5-\mathrm{NH}_{2}$ displayed spectra with minima at $221-222 \mathrm{~nm}$ and $209-210 \mathrm{~nm}$, and maxima at about $195 \mathrm{~nm}$ (Figs 3A and $3 \mathrm{~B}$ ), characteristic of $\alpha$-helical structure ${ }^{31,38}$. Analysis of these spectra showed that M5$\mathrm{NH}_{2}$ possessed $32.67 \% \alpha$-helicity in the case of SUVs formed from POPE and $60.40 \% \alpha$ helicity in the case of those formed from POPG (Figs 2A). In relation to lipid mimics of B. subtilis membranes, the peptide exhibited $53.40 \% \alpha$-helicity in the presence of SUVs formed from POPG and POPE in the molar ratio 70:30 and $52.62 \% \alpha$-helicity in the presence of those formed from lipid extract of the latter organism's membranes (Fig. 2B).

$\mathrm{M} 5-\mathrm{NH}_{2}$ is known to be unstructured in aqueous solution ${ }^{23}$ and in combination, these data indicate that the peptide generally undergoes a conformational rearrangement at a membrane interface to adopt $\alpha$-helical structure. This is enhanced by the presence of PG species or anionic lipid in general and is consistent with previous findings ${ }^{23}$, 25. Such interfacial conformational behaviour is typical of $\alpha$-helical AMPs and facilitates the generation of amphiphilic structures that constitute the membrane interactive forms of these peptides $9,10,12$. 


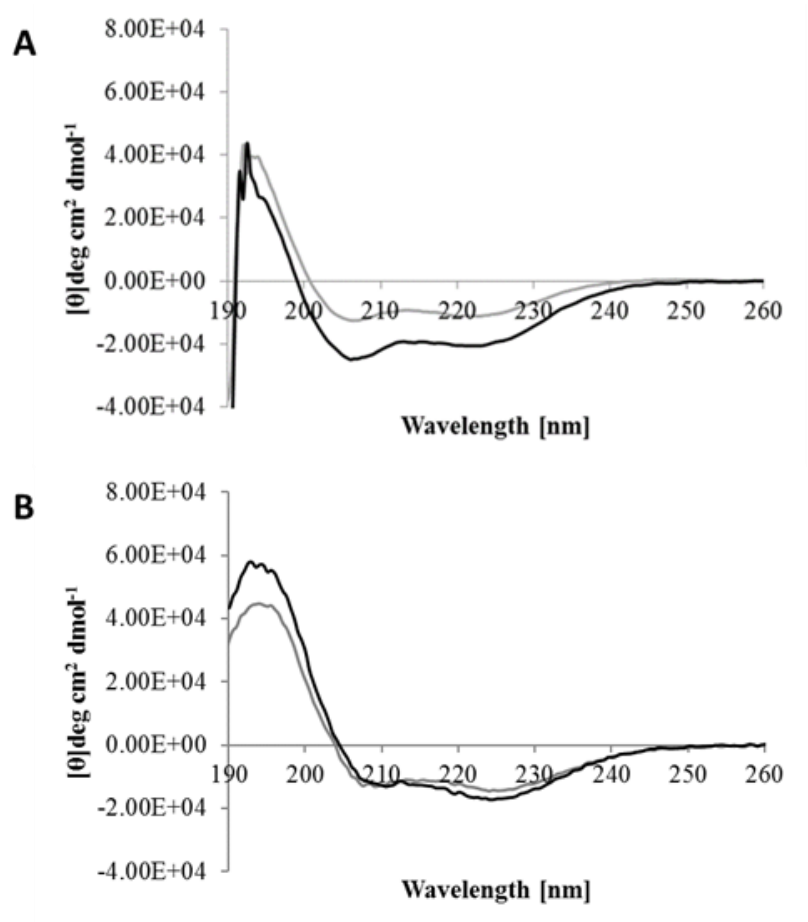

Fig. 2. CD spectral analysis of $\mathrm{M} 5-\mathrm{NH}_{2}$. In the presence of all SUVs examined, M5-NH2 displayed spectra with minima at $221-222 \mathrm{~nm}$ and $209-210 \mathrm{~nm}$ and maxima at about $195 \mathrm{~nm}$ (Figs. 2A and2B), which is characteristic of $\alpha$-helical structure ${ }^{31,38}$. In the case of SUVs formed from POPE (grey) and POPG (black), the peptide possessed 32.67\% and 60.40\% $\%$-helicity, respectively (Fig. 2A). In the presence of SUVs, which acted as lipid mimics of B. subtilis membranes, M5-NH2 possessed $52.62 \% \alpha$-helicity in the case of those formed from lipid extract of the organism's membranes and $53.40 \% \alpha$-helicity in the case of those formed from POPG and POPE in the molar ratio 70:30 (Fig. 2B). These data indicated that the peptide has a general ability to adopt $\alpha$-helical structure in the presence of membranes that is enhanced by PG species or the anionic lipid of bacterial membranes, a common feature in the action of many AMPs ${ }^{37}$.

The interaction of M5- $\mathrm{NH}_{2}$ with lipid monolayers. Lipid monolayers are highly effective for investigating the interaction of AMPs with membranes when precise control over membrane composition and compression is required ${ }^{33}$. Use of this methodology showed that $\mathrm{M} 5-\mathrm{NH}_{2}$ partitioned into lipid monolayers formed from either POPE or POPG with generally similar kinetics, exhibiting very rapid initial rates of insertion over circa five 
seconds (Fig. 3A). The peptide then inserted into these monolayers at a slower rate until maximal surface pressure changes were induced after approximately 500 seconds, indicating saturation with $\mathrm{M} 5-\mathrm{NH}_{2}$. However, these maximal surface pressure changes varied widely, with $3.5 \mathrm{mN} \mathrm{m}^{-1}$ observed in the case of monolayers formed from POPE, indicating relatively low levels of interaction by the peptide. In contrast, maximal surface pressure changes of $11.5 \mathrm{mN} \mathrm{m}^{-1}$ were observed in the case of monolayers formed from POPG, indicating high levels of interaction by $\mathrm{M} 5-\mathrm{NH}_{2}$ (Fig. 3A). In combination, these monolayer results clearly reflect the structural amphiphilicity of $\mathrm{M} 5-\mathrm{NH}_{2}$ (Fig. 1A) and reinforce the observation that the peptide has a strong interaction with either PG species or anionic lipid, in general

In relation to lipid mimics of $B$. subtilis membranes, $\mathrm{M} 5-\mathrm{NH}_{2}$ exhibited very rapid initial rates of insertion over circa five seconds in the case of both, monolayers formed from POPG and POPE in the molar ratio 70:30 and those formed from lipid extracted from the organism's membranes (Fig. 3B). However, afterwards, the peptide took circa ten times longer to achieve maximal surface pressure changes in monolayers composed of lipid extract as compared to the former monolayers (Fig. 3B), which may relate to the greater compositional complexity of monolayers formed from naturally occurring B. subtilis membranes ${ }^{41,42}$. The maximal surface pressure changes achieved by $\mathrm{M} 5-\mathrm{NH}_{2}$ were 9.0 $\mathrm{mN} \mathrm{m}^{-1}$ in monolayers formed from POPG and POPE in the molar ratio 70:30 and $8.0 \mathrm{mN}$ $\mathrm{m}^{-1}$ in those formed from lipid extract of the organism's membranes (Fig. 3B). These surface pressure changes are consistent with the apolar face of the $\alpha$-helical peptide interacting with the monolayer acyl chain region. Concomitantly, association of the polar face of $\alpha$-helical $\mathrm{M} 5-\mathrm{NH}_{2}$ with the monolayer head group region would be predicted to stabilise these hydrophobic interactions ${ }^{33}$. Comparable results have been reported for other $\alpha$-helical AMPs such as aurein 2.5, which kills bacteria using highly membranolytic mechanisms of action ${ }^{43}$. 

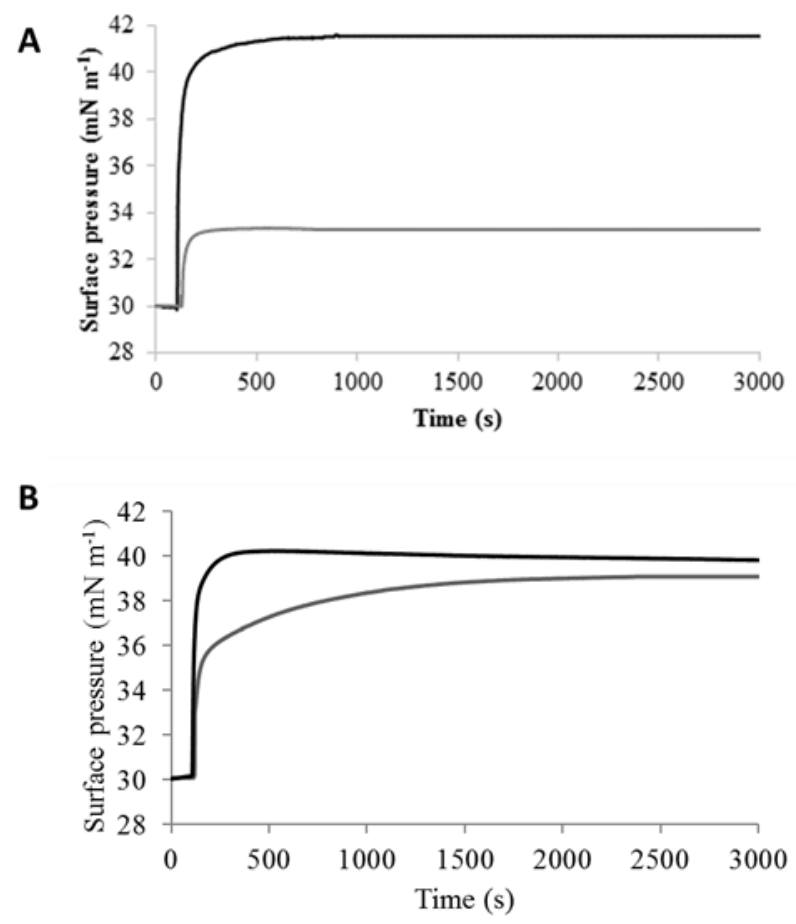

Fig. 3. The interaction of M5- $\mathrm{NH}_{2}$ with lipid monolayers. In the case of all monolayers examined, $\mathrm{M} 5-\mathrm{NH}_{2}$ showed high initial rates of insertion prior to achieving maximal surface pressure changes. These surface pressure changes were $3.5 \mathrm{mN} \mathrm{m}^{-1}$ in the case of monolayers formed from POPE (grey) and $11.5 \mathrm{mN} \mathrm{m}^{-1}$ in the case of those formed from POPG (black) (Fig. 3A), which clearly indicated an ability to interact with both zwitterionic and anionic lipid, reflecting the structural amphiphilicity of the peptide (Fig. 1A). For monolayers that acted as mimics of $B$. subtilis membranes, M5- $\mathrm{NH}_{2}$ displayed maximal surface pressure changes of $8.0 \mathrm{mN} \mathrm{m}^{-1}$ in the case of those formed from lipid extract of the organism's membranes and $9.0 \mathrm{mN} \mathrm{m}^{-1}$ in the case of those formed from POPG and POPE in the molar ratio 70:30 (Fig. 3B). These data clearly indicated that the peptide has a general ability to partition into membranes that is enhanced by PG species or the anionic lipid of bacterial membranes, a common characteristic in the activity of many AMPs 37 .

The membrane binding properties of M5-NH2. Another common approach to investigating the interaction of AMPs with membranes is to measure their lipid affinity using the fluorescence probe, FPE ${ }^{44}$. This was used to evaluate the ability of $\mathrm{M} 5-\mathrm{NH}_{2}$ to bind to membranes (Fig. 4). In all cases examined, the binding of the peptide to SUVs 
followed hyperbolic kinetics, with fluorescence rapidly increasing as the concentration of $\mathrm{M} 5-\mathrm{NH}_{2}$ rose. At a concentration of circa $150 \mu \mathrm{M}$, changes in fluorescence became independent of peptide concentration, indicating that SUVs were saturated with bound M5$\mathrm{NH}_{2}$ and no further binding of peptide could take place (Fig. 4). Analysis of these data indicated that the peptide bound to SUVs formed from POPG and POPE in the molar ratio 70:30 with a $\mathrm{K}_{\mathrm{d}}$ value of $10.44 \mu \mathrm{M}$. This shows that $\mathrm{M} 5-\mathrm{NH}_{2}$ would have a high affinity for $B$. subtilis membranes, which is around tenfold stronger than that shown by the peptide for membrane mimics of S. aureus ${ }^{23}$.

M5- $\mathrm{NH}_{2}$ also exhibited an affinity for both POPG and POPE (Fig. 4), which reflects the amphiphilic nature of the peptide (Fig. 1A). However, M5- $\mathrm{NH}_{2}$ bound POPG with a $\mathrm{K}_{\mathrm{d}}$ value of $7.46 \mu \mathrm{M}$, which is circa two-fold stronger than that shown in the case of POPE where a $K_{d}$ value of $14.7 \mu \mathrm{M}$ was observed. In combination, these results clearly indicate that the peptide has a high affinity for PG species or anionic lipid, in general. These results also indicate that binding to $B$. subtilis membranes is likely to involve both hydrophobic interactions and a major contribution from hydrophilic associations.

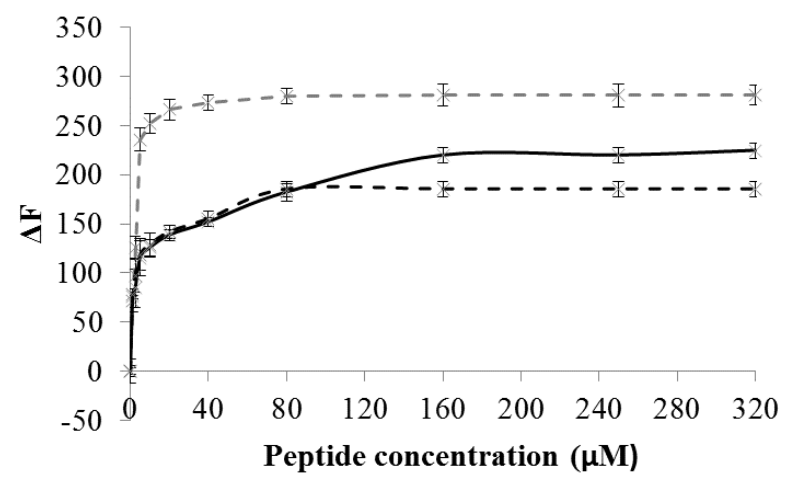

Fig. 4. Lipid binding affinity analysis of $\mathrm{M} 5-\mathrm{NH}_{2}$. The lipid affinity of $\mathrm{M} 5-\mathrm{NH}_{2}$ was measured by its $K_{d}$ value, which was derived from the maximum change in fluorescence induced by the peptide $(\Delta \mathrm{F})$ in FPE labelled SUVs. M5-NH $\mathrm{NH}_{2}$ bound SUVs formed from POPE (dashed black) with a $\mathrm{K}_{\mathrm{d}}$ value of $14.7 \mu \mathrm{M}$ and POPG (dashed grey) with a $\mathrm{K}_{d}$ value of $7.46 \mu \mathrm{M}$, demonstrating an affinity for both zwitterionic and anionic lipid, reflecting the structural amphiphilicity of the peptide (Fig. 1A). M5- $\mathrm{NH}_{2}$ bound SUVs formed from POPG and POPE in the molar ration 70:30 (black), which acted as lipid mimics of $B$. subtilis membranes, with a $\mathrm{K}_{\mathrm{d}}$ value of $10.44 \mu \mathrm{M}$. These data 
indicated that the peptide has a general affinity for membranes that was enhanced by PG species or the anionic lipid of bacterial membranes.

Thermodynamic analysis of $\mathrm{M} 5-\mathrm{NH}_{2}$ interaction with lipid monolayers. Thermodynamic analyses of area-pressure isotherms derived from monolayers are frequently used to inform changes in the architecture and properties of membranes induced by their interaction with AMPs ${ }^{33}$. Use of these analyses for monolayers formed from POPG and POPE in the molar ratio 70:30 (Fig. 5) showed that $\mathrm{C}_{s}^{-1}$ values increased with rising compression pressures, both in the presence and absence of $\mathrm{M} 5-\mathrm{NH}_{2}$ (Table 1) These $\mathrm{C}_{\mathrm{s}}^{-1}$ values lay in the range $9.16 \mathrm{mN} \mathrm{m}^{-1}$ to $40.37 \mathrm{mN} \mathrm{m}^{-1}$ (Table 1), indicating that the corresponding monolayers were generally in the liquid expanded phase and were highly fluid across the compression pressure range of $5 \mathrm{mN} \mathrm{m}^{-1}$ to $20 \mathrm{mN} \mathrm{m}^{-133}$. For a given compression pressure, the presence of $\mathrm{M} 5-\mathrm{NH}_{2}$ led to reductions in the $\mathrm{Cs}^{-1}$ values of monolayers (Table 1), which indicated that their lateral pressure and lipid packing density had decreased. These changes are reflected as increased monolayer elasticity and fluidity and are consistent with the partitioning of the peptide into these $B$. subtilis membrane mimics ${ }^{33}$. Similar results have been reported for other AMPs and, in these cases, changes in monolayer elasticity and fluidity have been primarily ascribed to membrane expansion via peptide - lipid head group interactions ${ }^{45}$.

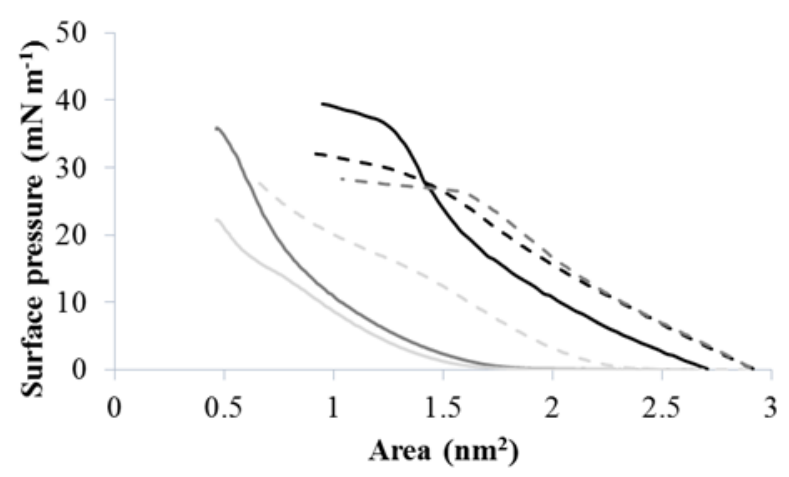

Fig. 5 Thermodynamic analysis of $\mathrm{M} 5-\mathrm{NH}_{2}$ interaction with lipid monolayers. Compression isotherm analysis of monolayers formed from POPE (grey), POPG (light grey) and POPG and POPE in the molar ratio 70:30 (black) in the absence of $\mathrm{M}^{-}-\mathrm{NH}_{2}$ (solid lines) and presence of the 
peptide (dotted lines) were used to generate values of $\mathrm{C}_{\mathrm{s}}^{-1}$ and $\Delta \mathrm{G}_{m i x}$ for lipid mimics of $B$. subtilis membranes. Analysis of these data showed that, for a given compression pressure, the presence of $\mathrm{M} 5-\mathrm{NH}_{2}$ led to reductions in the $\mathrm{C}_{\mathrm{s}}^{-1}$ values of these B. subtilis membrane mimics (Table 1), indicating that their lateral pressure and lipid packing density had decreased, consistent with partitioning of the peptide ${ }^{33}$. These analyses also showed that for a given compression pressure, the presence of $\mathrm{M} 5-\mathrm{NH}_{2}$ changed $\Delta \mathrm{G}_{m i x}$ values from $>0$ to $<0$ for $B$. subtilis membrane mimics (Table 1), indicating a thermodynamically stabilizing effect ${ }^{33}$ that was consistent with the promotion of increased membrane fluidity via peptide - lipid head group interactions ${ }^{45}$.

Compression isotherm analysis of monolayers formed from POPG and POPE in the molar ratio 70:30 (Fig. 5) was also used to determine values of $\Delta G_{m i x}$ for these lipid systems (Table 1). In the absence of $\mathrm{M} 5-\mathrm{NH}_{2}$, these $\Delta G_{m i x}$ values were $>0$, increasing from 4.56 to 20.07 as the compression pressure rose from $5 \mathrm{mN} \mathrm{m}^{-1}$ to $20 \mathrm{mN} \mathrm{m}^{-1}$ (Table 1). These results indicated that there were energetically unstable interactions between the individual lipid components of these monolayers, consistent with a phase separation ${ }^{33}$. However, in the presence of $\mathrm{M} 5-\mathrm{NH}_{2}$, these $\Delta G_{m i x}$ values were $<0$, decreasing from -2.99 to -13.84 across the same compression pressure range, indicating that there were attractive interactions between the individual monolayer components (Table 1). In combination, these data show that $B$. subtilis membrane mimics that were thermodynamically unstable $\left(\Delta G_{m i x}\right.$ $>0)$ were rendered thermodynamically stable $\left(\Delta G_{m i x}<0\right)$ by interaction with $\mathrm{M} 5-\mathrm{NH}_{2}{ }^{33}$. Similar thermodynamically stabilizing effects are induced in these membrane mimics by other AMPs which were attributed to peptide - lipid head-group interactions that promoted increased membrane fluidity, paralleling our $\mathrm{C}_{\mathrm{s}}^{-1}$ data (Table 1) ${ }^{45}$. It is well established that increases in the elasticity and fluidity of membranes are often associated with thinning of the bilayer and are common characteristics of the antibacterial action of AMPs ${ }^{46}$. 
Table 1. Thermodynamic properties of monolayer mimics of B. subtilis membranes

\begin{tabular}{ccccc}
$\begin{array}{c}\text { Surface } \\
\text { pressure } \\
\pi(\mathrm{mN}\end{array}$ & $\begin{array}{c}\text { POPG and } \\
\text { POPE in the }\end{array}$ & $\begin{array}{c}\text { POPG and POPE } \\
\text { in the molar ratio }\end{array}$ \\
$\left.\mathrm{m}^{-1}\right)$ & $\begin{array}{c}70: 30 \\
\end{array}$ & $\begin{array}{c}\Delta \mathrm{Gmix}\left(\mathrm{kJ} \mathrm{mol}^{-1}\right) \\
\mathrm{Cs}^{-1}\left(\mathrm{mN} \mathrm{m}^{-1}\right)\end{array}$ & & \\
& $-\mathrm{M} 5-$ & $+\mathrm{M} 5-$ & $-\mathrm{M} 5-$ & $+\mathrm{M} 5-$ \\
& $\mathrm{NH} 2$ & $\mathrm{NH} 2$ & $\mathrm{NH} 2$ & $\mathrm{NH} 2$ \\
\hline 5 & 25.52 & 9.16 & 4.56 & -2.99 \\
10 & 36.12 & 30.17 & 10.04 & -6.68 \\
15 & 37.20 & 32.98 & 14.66 & -9.86 \\
20 & 40.37 & 34.52 & 20.07 & -13.84 \\
\hline
\end{tabular}

Neutron diffraction localization of $\mathrm{M5}-\mathrm{NH}_{2}$ in lipid bilayers. Neutron scattering in conjunction with the substitution of hydrogen by its heavier isotope, deuterium, is frequently used to analyse the local structure, dynamics and interactions of multicomponent, biomolecular systems ${ }^{47}$. To assess the disposition of M5- $\mathrm{NH}_{2}$ in B. subtilis membrane mimics formed from POPG and POPE in the molar ratio 70:30, the N-terminal residue, L16, of the peptide was deuterated and its interaction with these membranes studied by neutron diffraction (Fig. 6), which is a form of elastic scattering ${ }^{47}$. The lamellar d-spacings obtained for these lipid membranes were $\mathrm{d}=53.6 \pm 0.2 \AA$, in the absence of the peptide, $\mathrm{d}=51.7 \pm 0.2 \AA$ in the presence of $\mathrm{M} 5-\mathrm{NH}_{2}$ and $\mathrm{d}=52.6 \pm 0.2 \AA$ in the presence of d-M5-NH2-L16. These changes in lamellar d-spacings indicate that the thickness and hydration of the bilayers were affected by interaction with the peptide ${ }^{48}$. The structure factors from Table 2 were employed to determine neutron diffraction density profiles for the interaction of $\mathrm{M} 5-\mathrm{NH}_{2}$ and d-M5- $\mathrm{NH}_{2}-\mathrm{L} 16$ with bilayers formed from POPG and POPE 
in the molar ratio 70:30 (Fig. 6). For these determinations, an $8 \%{ }^{2} \mathrm{H}_{2} \mathrm{O}$ contrast was used to provide an $\mathrm{H}_{2} \mathrm{O} /{ }^{2} \mathrm{H}_{2} \mathrm{O}$ ratio at which the mean neutron scattering length of the water mixture was zero ${ }^{48}$. The experimentally determined scattering density profiles of samples containing either $\mathrm{M} 5-\mathrm{NH}_{2}$ or d-M5- $\mathrm{NH}_{2}-\mathrm{L} 16$, scaled to the sum of the respective structure factors, were subtracted to reveal the position of the deuterated L16 residue within the bilayer. A positive difference between these two profiles was indicated at a distance of 5.5 $\pm 0.1 \AA$ from the membrane centre (Fig. 6). To determine the label position directly from the structure factors, a fit of a Gaussian model to the difference in structure factors in reciprocal space was performed ${ }^{36}$. The result indicated that the label position was at $5.7 \pm$ $0.1 \AA$ from the membrane centre, which is close to that obtained from the difference in experimentally determined density profiles. The difference in the fitted density profile, calculated with 5 structure factors, is less 'wavy' than the difference in the experimentally determined profiles, as in this case, the origin is solely the Fourier truncation error. These results locate $\mathrm{L} 16$ of $\mathrm{M} 5-\mathrm{NH}_{2}$ within the acyl chain region of the $\mathrm{B}$ subtilis membrane mimics.

For scattering density profiles, the water layer thickness of bilayers, $d_{w}$, is defined by twice the distance of the unit cell edge to the position of half of the scattering length maximum, $\mathrm{z}_{\mathrm{w}}{ }^{36}$. For example, the water boundary defined by $\mathrm{z}_{\mathrm{w}}$ for a leaflet of bilayers formed from POPG and POPE in the molar ratio 70:30 in the presence of d-M5- $\mathrm{NH}_{2}-\mathrm{L} 16$ is indicated in Fig. 6 by the thin vertical line. Analysis of Fig. 6 showed that for these bilayers, $\mathrm{d}_{\mathrm{w}}$ decreases from $9.2 \pm 0.2 \AA$ to $8.4 \pm 0.2 \AA$ in the presence of $\mathrm{M} 5-\mathrm{NH}_{2}$ and 8.6 $\pm 0.2 \AA$ in the case of $\mathrm{d}-\mathrm{M} 5-\mathrm{NH}_{2}-\mathrm{L} 16$. The distance between the density peaks corresponding to the lipid head-groups in scattering density profiles is indicative of the thickness of the bilayer ${ }^{36}$ and in the case of those formed from POPG and POPE in the molar ratio 70:30, this distance was $36.8 \pm 0.2 \AA$ in the absence of the peptide (Fig. 6). This distance was decreased to $35.0 \pm 0.2 \AA$ in the presence $\mathrm{M} 5-\mathrm{NH}_{2}$ and to $35.06 \pm 0.2 \AA$ in the presence of d-M5- $\mathrm{NH}_{2}-\mathrm{L} 16$, signifying a reduction in the bilayer thickness of around $1.8 \AA$. Taken together, these data indicate that the peptide modulates structure in the acyl chain region of $B$. subtilis membranes and induces a membrane thinning effect; this is 
consistent with the thermodynamic data (Fig. 5). Comparable decreases in bilayer thickness have been reported for a number of other membrane thinning AMPs, such as magainin 2 and BP100 ${ }^{49}$.

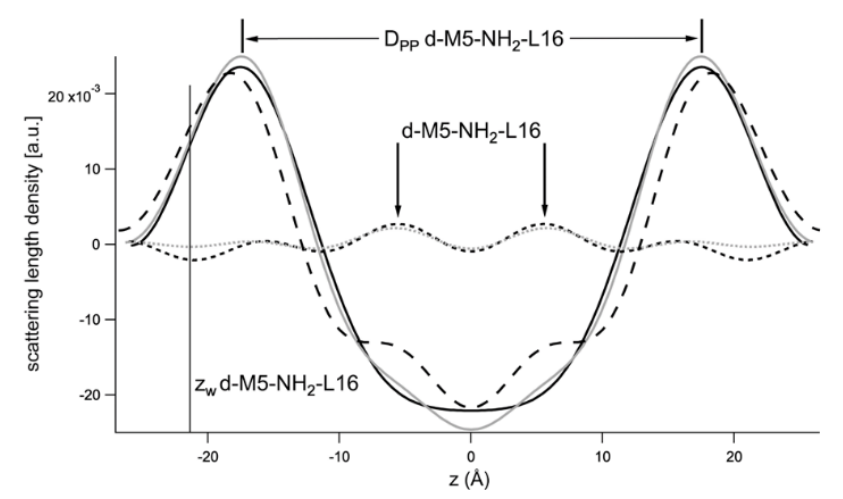

Fig. 6. Neutron diffraction studies on $\mathrm{M} 5-\mathrm{NH}_{2} /$ d-M5- $-\mathrm{NH}_{2}-\mathrm{L} 16$ - membrane interactions. Neutron scattering density profiles were produced for a transection taken perpendicular to the surface of bilayers formed from POPG and POPE in the molar ratio 70:30, which acted as lipid mimics of $B$. subtilis membranes. These bilayers were either in the absence of peptide (dashed black), or in the presence of either M5- $\mathrm{NH}_{2}$ (black) or d-M5- $\mathrm{NH}_{2}-\mathrm{L} 16$ (grey), at $8 \%{ }^{2} \mathrm{H}_{2} \mathrm{O}$. The difference between the experimentally determined scattering density profiles of samples with either M5- $\mathrm{NH}_{2}$ or d-M5- $\mathrm{NH}_{2}-\mathrm{L} 16$ (dotted black), and a Gaussian model fitted to the difference in structure factors in reciprocal space (dotted grey) ${ }^{36}$ revealed the position of the deuterated L16 residue within the bilayer. In relation to the membrane centre $\left(z=0 \AA{ }^{48}\right)$, a positive difference between the experimentally determined profiles was revealed at a distance of $z= \pm 5.5 \pm 0.1 \AA$, and at a distance of $\mathrm{z}= \pm 5.7 \pm 0.1 \AA$ for the Gaussian model fitted to the difference in structure factors in reciprocal space. In both cases, these differences are attributed to L16 of $\mathrm{M} 5-\mathrm{NH}_{2}$ residing within the acyl chain region of the bilayer. The water boundary, $\mathrm{z}_{\mathrm{w}}$, for a leaflet of bilayers formed from POPG and POPE in the molar ratio 70:30 in the presence of d-M5- $\mathrm{NH}_{2}-\mathrm{L} 16$ is indicated by the thin vertical line. The position of the density peaks corresponding to the lipid head-group regions of these bilayers provides information regarding their thickness ${ }^{36}$. The distance between these lipid head-groups, or density profile peaks ( $\left.\mathrm{D}_{\mathrm{pp}}\right)$, was $36.8 \pm 0.2 \AA$ in the absence of peptide, which was decreased to $35.0 \pm 0.2 \AA$ in the presence M5- $\mathrm{NH}_{2}$ and $35.06 \pm 0.2$ $\AA$ in the presence of d-M5- $\mathrm{NH}_{2}-\mathrm{L} 16$, as is indicated above. In combination, these data indicate that 
the peptide modulates structure in the acyl chain region of $B$. subtilis membranes. This effect decreased the bilayer thickness by circa $1.8 \AA$, or $5 \%$, inducing a membrane thinning effect. Comparable decreases in bilayer thickness have been reported for a number of other membrane thinning AMPs ${ }^{49}$.

Table 2. Experimental structure factors $F(h)$, corrected and scaled, as described in the text

\begin{tabular}{cccccc}
\hline $\begin{array}{c}\text { POPG and POPE } \\
\text { in the molar ratio }\end{array}$ & $F(1)$ & $F(2)$ & $F(3)$ & $F(4)$ & $F(5)$ \\
$70: 30$ & & & & & \\
\hline$+\mathrm{M}^{2} \mathrm{NH}_{2}$ & $0.498 \pm$ & $-0.254 \pm$ & $-0.215 \pm$ & -0.033 & \\
& 0.0017 & 0.0040 & 0.0030 & \pm 0.0070 & \\
& $0.471 \pm$ & $-0.252 \pm$ & $-0.203 \pm$ & $-0.04 \pm$ & $0.03 \pm$ \\
\hline
\end{tabular}

\section{Discussion}

By far the biggest group of naturally occurring AMPs are those that adopt amphiphilic $\alpha$-helical conformations. This form of secondary structure has been used as a template for the production of numerous synthetic peptides with potential as antimicrobials ${ }^{50}$. A number of these AMPs are based on a periodicity of lysine residues alternating with alanine and leucine residues that is designed to optimize the levels of amphiphilicity and $\alpha$-helicity of the parent structure (LAK AMPs) ${ }^{51}$. The use of these residues minimises production costs and LAK AMPs have been employed in a number of capacities, ranging from serving as the membrane disrupting domain of targeted pro-apoptotic peptides ${ }^{52}$ to enhancing the antimicrobial action of sonosensitizers when conjugated with these molecules ${ }^{53}$. LAK AMPs also serve as potent, broad range antibacterial agents ${ }^{51}$ with activity against MDR pathogens such as A. baumannii, and the ability to synergize the action of conventional antibiotics against these pathogens ${ }^{54}$. A major example of LAK AMPs is modelin-5$\mathrm{CONH}_{2}\left(\mathrm{M} 5-\mathrm{NH}_{2}\right)$ and in the present study, we have sought to investigate mechanisms 
underpinning the activity of the peptide against B. subtilis ${ }^{19-25}$. Here M5-NH 2 was found to kill B. subtilis at micromolar levels of peptide $(8.47 \mu \mathrm{M})$. Such levels of antibacterial activity are desirable when screening peptides for the potential to serve as leads in designing therapeutic AMPs ${ }^{10}$.

It is well established that the antibacterial action of all known AMPs involves interaction with membranes and $\mathrm{M} 5-\mathrm{MH}_{2}$ showed a clear ability to interact with those formed from the native lipids of B. subtilis (Figs 3B, 4 and 5). However, to gain a deeper understanding of these interactions and to enable a more detailed data analysis in compression isotherm studies and neutron diffraction investigations (Figs 5 and 6), B. subtilis membranes were modelled by synthetic lipid mixes rather than bacterial lipid extracts. The majority of the native lipids in $B$. subtilis membranes are various phosphatidylglycerol (PG) species (70 $\%$ ) with the remainder comprising a variety of phosphatidylethanolamine (PE) species ${ }^{41}$, 42. Accordingly, synthetic lipid mimics of B. subtilis membranes were formed from the representative PG species, POPG, and the representative PE species, POPE, in the molar ratio 70:30. Control experiments established that $\mathrm{M} 5-\mathrm{MH}_{2}$ showed similar conformational behaviour and lipid interactivity between these synthetic lipid mimics and native lipid mimics of B. subtilis membranes (Figs 2 and 3). Whilst it is recognised that these synthetic systems lack a range of non-lipid components, they are well documented as providing information regarding the important role of lipid membrane components in relation to the mode of action used by AMPs ${ }^{33}$.

In general, the interaction of AMPs with the bacterial membrane leads to the death of these organisms via membranolysis and a number of models have been presented to describe this process, such as the barrel stave, toroidal pore, carpet and tilted-type mechanisms ${ }^{37}$. Based on similarities to these models, a synthesis of the data presented here permits a scheme to be constructed that describes the ability of $\mathrm{M} 5-\mathrm{MH}_{2}$ to kill B. subtilis. In the first step of this scheme, the strongly cationic peptide targets anionic components of B. subtilis membranes, including PG species. $\mathrm{M} 5-\mathrm{MH}_{2}$ then binds to these membranes with high affinity $\left(\mathrm{K}_{\mathrm{d}}=10.44 \mu \mathrm{M}\right.$, Fig. 4) to adopt $\alpha$-helical structure (> $50 \%$, Fig. $\left.2 \mathrm{~B}\right)$, the membrane interactive form of $\mathrm{M} 5-\mathrm{MH}_{2}$ for this organism. The peptide is strongly attracted to anionic lipid or PG species and the major driver of this conformational change is the 
preponderance of these latter species in the membranes of B. subtilis. These PG species show a much stronger propensity to induce $\alpha$-helical structure in the peptide (> 60\%, Fig. $2 \mathrm{~A}$ ) as compared to PE species ( $<40 \%$, Fig $2 \mathrm{~A}$ ).

In the next step of our scheme, the high levels of $\alpha$-helical structure possessed by the peptide in the presence of the organism's membranes (Fig. 2A) drive it to partition strongly into these membranes $\left(\Delta \pi \geq 8.0 \mathrm{mN} \mathrm{m}^{-1}\right.$, Fig. 3B) and to interact with both their head group and hydrophobic core regions (Figs 3B and 6). Neutron diffraction studies clearly showed that the N-terminal residue, $\mathrm{L} 16$, of $\mathrm{M} 5-\mathrm{MH}_{2}$ was located around $5.5 \AA$ from the centre of B. subtilis membranes and in the acyl chain region of these membranes (Fig. 6). The underlying driver of the peptide's insertion into B. subtilis membranes appears to be the high amphiphilicity of the $\alpha$-helical structure adopted in the presence of these membranes $(<\mu H>=0.75$, Fig. 1). Indeed, the strongly $\alpha$-helical peptide showed very high levels of partitioning into membranes formed from $\mathrm{PG}$ species $\left(\Delta \pi=11.5 \mathrm{mN} \mathrm{m}^{-1}\right.$, Fig. 3A). However, the loss of amphiphilic $\alpha$-helical structure by $\mathrm{M}^{-}-\mathrm{MH}_{2}(>20 \%$, Fig. $2 \mathrm{~A}$ ) in the presence of membranes formed from PE species led to around a threefold reduction in the ability of the peptide to partition into these membranes $\left(\Delta \pi=3.5 \mathrm{mN} \mathrm{m}^{-1}\right.$, Fig. 3A). These early steps in the interactions of the peptide with $B$. subtilis membranes are typical of $\alpha$ helical AMPs with activity at the interface and are common to most models used to describe the membrane interactions of thee peptide ${ }^{37}$. It is generally accepted that the exothermic action of $\alpha$-helix formation contributes strongly to the enthalpy driven mechanisms of membrane insertion used by these AMPs ${ }^{55}$.

The partitioning of M5- $\mathrm{NH}_{2}$ into B. subtilis membranes promotes membrane thinning effects and this was directly demonstrated by neutron diffraction studies where insertion by the peptide was shown to decrease membrane thickness by circa $1.8 \AA$ or $5 \%$ of its width (Fig. 6). Insertion by M5-NH 2 was also found to promote increases in the surface area $\left(\mathrm{C}_{\mathrm{s}}^{-}\right.$ ${ }^{1} \downarrow$, Table 1$)$ and fluidity $\left(\Delta \mathrm{G}_{m i x}>0 \rightarrow<0\right.$, Table 1$)$ of $B$. subtilis membranes, which is consistent with a thinning effect ${ }^{46}$. Similar results have been reported for other $\alpha$-helical AMPs, such as magainin 2, and in these cases, membrane thinning effects have resulted from the insertion of these peptides into the membrane with their $\alpha$-helices orientated parallel to the lipid surface ${ }^{49,56}$. Several studies have suggested that $\mathrm{M} 5-\mathrm{NH}_{2}$ may also 
partition horizontally into bacterial membranes ${ }^{23-25}$, which could help explain the membrane thinning effect observed for the interaction of the peptide with membranes of $B$. subtilis (Table 1, Fig. 6). Indeed, it would seem that horizontally partitioning into these membranes would be aided by the even distribution of positive charge along the $\alpha$-helical long axis of the peptide (Fig. 1A) ${ }^{23-25}$. Consistent with the high affinity of M5-NH2 for PG species $\left(K_{d}=7.46 \mu \mathrm{M}\right.$, Fig. 4), adopting this orientation would allow the peptide's lysine groups (Fig. 1A) to interdigitate with the head groups of these species (Fig. 6). Indeed, the membranes of this organism include very high levels of diphosphatidylglycerol ${ }^{41,42}$, and it is well established that anionic moieties in the head group of this PG species are far more accessible to AMPs than those of other bilayer lipids ${ }^{57}$. Horizontally partitioning into the membranes of B. subtilis, would also help drive penetration of the peptide's alanine and leucine residues (Fig. 1A) into the hydrophobic core region of the bilayer, given the affinity of M5-NH 2 for zwitterionic lipid ( $\mathrm{K}_{\mathrm{d}}=14.7 \mu \mathrm{M}$, Fig. 4). Neutron diffraction studies showed that the membrane thinning ability of the peptide involved modulating the structure of the acyl chain region by its N-terminal residue, L16 (Fig. 6). Presumably, this action would promote the relaxation of acyl chains and lower the order of these lipid tails, as reported for other membrane thinning AMPs $49,56$.

In the latter stages of our putative scheme for the ability of $\mathrm{M} 5-\mathrm{MH}_{2}$ to kill B. subtilis, membrane insertion and thinning effects by the peptide induce high levels of membranolysis (> $55 \%$ ), resulting in the death of the organism. Based on the data presented here, it is not possible to definitively assign the antibacterial action of $\mathrm{M} 5-\mathrm{NH}_{2}$ to any particular model of membrane interaction. Given the relatively short length of the peptide, it seems unlikely that it would be able to form a membrane spanning pore, such as the barrel stave model proposed for a number of AMPs ${ }^{37}$. However, the mode of membrane partitioning shown here for the peptide is often associated with the toroidal pore and carpet models ${ }^{37}$, and these models have previously been predicted to describe the antibacterial action of $\mathrm{M} 5-\mathrm{MH}_{2}{ }^{23-25}$. According to the first of these models, horizontal insertion and thinning by the peptide would destabilize the integrity of $B$. subtilis, membranes and lead to lysis through the generation of transmembrane channels formed by the intercalation of reorientated $\mathrm{M} 5-\mathrm{MH}_{2}$ molecules with lipid. In the second of these models, a high density 
of the horizontally orientated peptide would accumulate on the surface of B. subtilis membranes, which would promote thinning and dissolution of the bilayer via a detergentlike action that does not involve channel formation ${ }^{37}$. Neutron diffraction studies have revealed other mechanisms for the lysis of bilayers by horizontally orientated AMPs involving membrane thinning but not leading to pore or channel formation, such as that recently described for aurein 1.2. The binding of the peptide to membranes induced membrane thinning, accompanied by a major redistribution of PG species in the outer leaflet that appeared to promote the formation of complexes between lipid and aurein 1.2 and the compromise of membrane integrity ${ }^{58}$. A further possibility based on the architecture of $\mathrm{M} 5-\mathrm{MH}_{2}$ may be that the mode of membrane partitioning used by the peptide leads to the use of a tilted-type mechanism. The peptide shows the potential to form $\alpha$-helical structure with a hydrophobicity gradient that increases towards the N-terminal residue, $\mathrm{L16}$, of $\mathrm{M} 5-\mathrm{MH}_{2}$ (Fig. 1B) and this form of secondary structure is a defining characteristic of tilted peptides that promotes their oblique membrane insertion $30,37$. Clearly, the lysis of $B$. subtilis membranes by a tilted mechanism would be consistent with the residence of L16 in the acyl chain region of these membranes (Fig. 6). Lysine residues possessed by the peptide could also play a role in promoting tilted membrane penetration via the snorkelling mechanism, which would allow the amine groups of these residues to remain associated with the lipid head-group region of membranes. Concomitantly, their long hydrocarbon side chains extend into the membrane's hydrophobic region, permitting deeper levels of penetration by $\mathrm{M} 5-\mathrm{MH}_{2}$, as reported for other AMPs that appear to use this structure to facilitate their antibacterial action ${ }^{59}$. Taken in combination, these observations suggest that the use of a tilted mechanism by $\mathrm{M} 5-\mathrm{NH}_{2}$ to lyse the membranes of $B$. subtilis would involve roles for both PE species and PG species in relation to orientating the peptide and modulating the overall effect of its action on lipid organisation and membrane architecture. These observations also reinforce the view that to fully characterise the antimicrobial action of AMPs, it is necessary to consider the properties of both of these peptides and their target membranes ${ }^{37}$.

As a final comment, it is interesting to note that B. subtilis shows historical similarity to A. baumannii, in that it was first isolated from soil over a century ago and is generally 
considered to be non-pathogenic ${ }^{60}$. However, since the $1960 \mathrm{~s}$, strains of B. subtilis have been responsible for a number of serious infections, generally in individuals who are critically ill or immunocompromised ${ }^{61,62}$. A very recent study, reported that the organism is increasingly prevalent in hospitalized patients and is sufficiently equipped with virulence mechanisms to behave as a human pathogen. It has been recommended that the identification of B. subtilis and other members of this genus should be routinely performed, particularly when samples derive from patients who are immunocompromised or have a pre-existing disease condition ${ }^{63}$. B. subtilis is also commonly found in probiotic formulations and there are now growing concerns about the potential of this organism and other species of its genus for virulence when used as a dietary supplement ${ }^{62-64}$. Moreover, the resistance of $B$. subtilis to antibiotics has been demonstrated ${ }^{62}$ and it is becoming increasingly clear that it possesses the ability to resist AMPs; this would seem to make the development of $\mathrm{M} 5-\mathrm{MH}_{2}$ as an agent against the organism timely ${ }^{65,66}$. Indeed, B. subtilis may only be one example of an emerging problem which, for example, appears to include bacteria of the genus, Lactobacillus, another group of Gram-positive organisms used as probiotics 67 . These bacteria are generally considered to be harmless but strains are emerging with pathogenic relevance to elderly and immunocompromised patients ${ }^{68}$, as in a recent case of acute cholecystitis caused by vancomycin-resistant Lactobacilli ${ }^{69}$.

\section{Conclusion}

In summary, $\mathrm{M} 5-\mathrm{NH}_{2}$ is a synthetic antibacterial agent with very low levels of haemolysis ${ }^{26}$, and here it has been shown that the peptide has a potent ability to kill $B$. subtilis via membranolytic modes of action. Potentially, this action could be facilitated by a number of mechanisms, particularly tilted peptide formation: indeed, the data presented here could support the use of a recently reported, novel, tilted-type antibacterial mechanism. Using this mechanism, AMPs accumulate in the outer leaflet of the bacterial membrane and form pore-like structures by inserting in an oblique orientation. The resulting shallow pores promote rapid membrane thinning, leading to progressive 
disintegration and exfoliation of the outer leaflet at the sites of pore formation, which then induces cell death ${ }^{70}$.

\section{Conflicts of interest}

The authors declare no conflict of interest.

\section{Author contribution}

S.R.D, T.H, K.B. F.H and D.A.P. designed the research. K.B. synthesised the peptide. S.R.D and T.H performed research. S.R.D, T.H, and F.H analysed data. S.R.D, T.H, F.H and D.A.P. wrote the manuscript.

\section{Acknowledgments}

This project has received funding from the European Union's Seventh Framework Programme for research, technological development and demonstration under the NMI3-II Grant number 283883. The peptides $\mathrm{M}^{5}-\mathrm{NH}_{2}$ (KLAKKLAKLAKLAKAL-CONH$\left.)_{2}\right)$ and d-M5-NH2-L16 (KLAKKLAKLAKLAKAL(d16)-CONH 2 ) were partially funded by the Biochemical Society Eric Reid Fund for Methodology.

\section{References}

1. M. Frieri, K. Kumar and A. Boutin, Journal of Infection and Public Health, 2017, 10, 369378.

2. World Health Organization, Antimicrobial resistance: global report on surveillance 2014., Geneva, Switzerland., 2014.

3. World Health Organisation., Global action plan on antimicrobial drug resistance, Geneva, Switzerland, 2015.

4. J. O'Neill, Tackling drug-resistant infections globally: final report and recommendations., 2016. 
5. World Health Organisation, Global Priority List of Antibiotic-resistant Bacteria to Guide Research, Discovery, and Development of New Antibiotics., Geneva, Switzerland, 2017.

6. A. Howard, M. O'Donoghue, A. Feeney and R. D. Sleator, Virulence, 2012, 3, 243-250.

7. C.-R. Lee, J. H. Lee, M. Park, K. S. Park, I. K. Bae, Y. B. Kim, C.-J. Cha, B. C. Jeong and S. H. Lee, Frontiers in Cellular and Infection Microbiology, 2017, 7, 55.

8. S. S. Ahmed, E. Alp, J. Hopman and A. Voss, Journal of Infectious Diseases and Therapy, 2017, 4.

9. M. E. Pachón-Ibáñez, Y. Smani, J. Pachón and J. Sánchez-Céspedes, FEMS Microbiology Reviews, 2017, 41, 323-342.

10. P. Kumar, J. N. Kizhakkedathu and S. K. Straus, Biomolecules, 2018, 8, 4.

11. G. S. Wang, X. Li and Z. Wang, Nucleic Acids Research, 2016, 44, D1087-D1093.

12. M. Mahlapuu, J. Håkansson, L. Ringstad and C. Björn, Frontiers in Cellular and Infection Microbiology, 2016, 6, 194.

13. K. B. Steinbuch and M. Fridman, MedChemComm, 2016, 7, 86-102.

14. D. A. Phoenix, S. R. Dennison and F. Harris, in Antimicrobial Peptides, Wiley-VCH Verlag GmbH \& Co. KGaA, 2013, DOI: 10.1002/9783527652853.ch1, pp. 1-37.

15. J. Z. Kubicek-Sutherland, H. Lofton, M. Vestergaard, K. Hjort, H. Ingmer and D. I. Andersson, The Journal of antimicrobial chemotherapy, 2017, 72, 115-127.

16. G. Yu, D. Y. Baeder, R. R. Regoes and J. Rolff, Proceedings. Biological sciences, 2018, 285.

17. G. Z. Yu, D. Y. Baeder, R. R. Regoes and J. Rolff, Antimicrobial Agents and Chemotherapy, 2016, 60, 1717-1724.

18. K. E. Greber and M. Dawgul, Current topics in medicinal chemistry, 2017, 17, 620-628.

19. USA Pat., 6875744, 2005.

20. S. R. Dennison, F. Harris, T. Bhatt, J. Singh and D. A. Phoenix, Molecular and Cellular Biochemistry, 2009, 332, 43-50.

21. S. R. Dennison, F. Harris, T. Bhatt, J. Singh and D. A. Phoenix, Molecular and Cellular Biochemistry, 2010, 333, 129-135.

22. R. Bessalle, A. Gorea, I. Shalit, J. W. Metzger, C. Dass, D. M. Desiderio and M. Fridkin, Journal of Medicinal Chemistry, 1993, 36, 1203-1209. 
23. S. R. Dennison, L. H. G. Morton and D. A. Phoenix, Biochimica et Biophysica Acta (BBA) - Biomembranes, 2012, 1818, 2094-2102.

24. S. R. Dennison and D. A. Phoenix, Biochemistry, 2011, 50, 10898-10909.

25. S. R. Dennison and D. A. Phoenix, Biochemistry, 2011, 50, 1514-1523.

26. S. R. Dennison and D. A. Phoenix, European Biophysics Journal with Biophysics Letters, 2014, 43, 423-432.

27. R. Borriss, A. Danchin, C. R. Harwood, C. Medigue, E. P. C. Rocha, A. Sekowska and D. Vallenet, Microbial biotechnology, 2018, 11, 3-17.

28. D. A. Phoenix, S. R. Dennison and F. Harris, in Antimicrobial Peptides, Wiley-VCH Verlag GmbH \& Co. KGaA, 2013, DOI: 10.1002/9783527652853.ch4, pp. 115-144.

29. D. A. Phoenix and F. Harris, Molecular Membrane Biology, 2002, 19, 1-10.

30. F. Harris, A. Daman, J. Wallace, S. R. Dennison and D. A. Phoenix, Current Protein \& Peptide Science, 2006, 7, 529-537.

31. S. Dennison, L. Morton, F. Harris and D. A. Phoenix, Biochemistry, 2016, 55(27), 37353751.

32. L. Whitmore, B. Woollett, A. J. Miles, R. W. Janes and B. A. Wallace, Structure, 2010, 18, 1267-1269.

33. S. R. Dennison, F. Harris and D. A. Phoenix, in Advances in Planar Lipid Bilayers and Liposomes, eds. A. Iglic and C. V. Kulkarni, Elsevier Science, London, UK., 2014.

34. J. Todd, Introduction to the Constructive Theory of Functions, Academic Press, New York, 1963.

35. T. Hauß, Journal of Large Scale Research Facilities, 2016, 2, A94-A98.

36. S. Dante, T. Hauss and N. A. Dencher, Biophys J, 2002, 83, 2610-2616.

37. D. A. Phoenix, S. R. Dennison and F. Harris, in Antimicrobial Peptides, Wiley-VCH Verlag GmbH \& Co. KGaA, 2013, DOI: 10.1002/9783527652853.ch5, pp. 145-180.

38. S. R. Dennison, F. Harris and D. A. Phoenix, Biochimie, 2017, 137, 29-34.

39. M.-T. Lee, Advances in Physics: X, 2018, 3, 1408428.

40. N. Shagaghi, E. A. Palombo, A. H. A. Clayton and M. Bhave, World Journal of Microbiology and Biotechnology, 2018, 34, 62. 
41. F. Sebastiani, R. Harvey, S. Khanniche, J.-B. Artero, M. Haertlein and G. Fragneto, The European Physical Journal Special Topics, 2012, 213, 355-365.

42. D. G. Bishop, L. Rutberg and B. Samuelsson, Eur J Biochem, 1967, 2, 448-453.

43. S. R. Dennison, L. H. G. Morton, A. J. Shorrocks, F. Harris and D. A. Phoenix, Colloids and Surfaces B: Biointerfaces, 2009, 68, 225-230.

44. P. M. Matos, H. G. Franquelim, M. A. Castanho and N. C. Santos, Biochim Biophys Acta, 2010, 1798, 1999-2012.

45. S. R. Dennison, L. H. G. Morton, F. Harris and D. A. Phoenix, Chemistry and Physics of Lipids, 2008, 151, 92-102.

46. H. Sato and J. B. Feix, Biochimica et Biophysica Acta (BBA) - Biomembranes, 2006, 1758, 1245-1256.

47. J. F. Ankner, W. T. Heller, K. W. Herwig, F. Meilleur and D. A. Myles, Current protocols in protein science, 2013, Chapter 17, Unit17.16.

48. G. King and S. White, Biophys. J., 1986, 49, 1047-1054.

49. S. L. Grage, S. Afonin, S. Kara, G. Buth and A. S. Ulrich, Frontiers in Cell and Developmental Biology, 2016, 4, 65.

50. L. E. Uggerhoj, T. J. Poulsen, J. K. Munk, M. Fredborg, T. E. Sondergaard, N. FrimodtMoller, P. R. Hansen and R. Wimmer, Chembiochem, 2015, 16, 242-253.

51. M. M. Javadpour, M. M. Juban, W.-C. J. Lo, S. M. Bishop, J. B. Alberty, S. M. Cowell, C. L. Becker and M. L. McLaughlin, Journal of Medicinal Chemistry, 1996, 39, 3107-3113.

52. K. A. Min, P. Maharjan, S. Ham and M. C. Shin, Archives of Pharmacal Research, 2018, 41, 594-616.

53. D. Costley, H. Nesbitt, N. Ternan, J. Dooley, Y. Y. Huang, M. R. Hamblin, A. P. McHale and J. F. Callan, Int J Antimicrob Agents, 2017, 49, 31-36.

54. D. M. McGrath, E. M. Barbu, W. H. Driessen, T. M. Lasco, J. J. Tarrand, P. C. Okhuysen, D. P. Kontoyiannis, R. L. Sidman, R. Pasqualini and W. Arap, Proc Natl Acad Sci U S A, 2013, 110, 3477-3482.

55. J. Seelig, Biochimica et Biophysica Acta (BBA) - Biomembranes, 2004, 1666, 40-50.

56. M. Malmsten, Upsala Journal of Medical Sciences, 2014, 119, 199-204.

57. R. N. Lewis and R. N. McElhaney, Biochim Biophys Acta, 2009, 1788, 2069-2079. 
58. D. K. Rai and S. Qian, Scientific Reports, 2017, 7, 3719.

59. S. R. Dennison, F. Harris and D. A. Phoenix, Protein and Peptide Letters, 2005, 12, 2729.

60. M. Suva, V. Sureja and D. Kheni, Journal of Current Research in Scientific Medicine, $2016,2,65-72$.

61. Y. L. Jeon, J. J. Yang, M. J. Kim, G. Lim, S. Y. Cho, T. S. Park, J. T. Suh, Y. H. Park, M. S. Lee, S. C. Kim and H. J. Lee, Journal of medical microbiology, 2012, 61, 1766-1769.

62. S. Hempel, S. Newberry, A. Ruelaz, Z. Wang, J. N. V. Miles, M. J. Suttorp, B. Johnsen, R. Shanman, W. Slusser, N. Fu, A. Smith, B. Roth, J. Polak, A. Motala, T. Perry and P. G. Shekelle, Evidence Report/Technology Assessment, 2011, 1-645.

63. F. Celandroni, S. Salvetti, S. A. Gueye, D. Mazzantini, A. Lupetti, S. Senesi and E. Ghelardi, PLoS One, 2016, 11, e0152831.

64. F. M. F. Elshaghabee, N. Rokana, R. D. Gulhane, C. Sharma and H. Panwar, Front Microbiol, 2017, 8, 1490.

65. S. Omardien, S. Brul and S. A. J. Zaat, Frontiers in Cell and Developmental Biology, 2016, 4, 111 .

66. T. T. Tran, J. M. Munita and C. A. Arias, Annals of the New York Academy of Sciences, $2015,1354,32-53$.

67. E. J. Quinto, P. Jim“|'nez, I. Caro, J. s. Tejero, J. Mateo and T. s. Girb”|'s, Food and Nutrition Sciences, 2014, Vol.05No.18, 11.

68. J. P. Cannon, T. A. Lee, J. T. Bolanos and L. H. Danziger, European journal of clinical microbiology \& infectious diseases : official publication of the European Society of Clinical Microbiology, 2005, 24, 31-40.

69. J. Chery, D. Dvoskin, F. P. Morato and B. Fahoum, International Journal of Surgery Case Reports, 2013, 4, 662-664.

70. A. Pyne, M. P. Pfeil, I. Bennett, J. Ravi, P. Iavicoli, B. Lamarre, A. Roethke, S. Ray, H. B. Jiang, A. Bella, B. Reisinger, D. Yin, B. Little, J. C. Munoz-Garcia, E. Cerasoli, P. J. Judge, N. Faruqui, L. Calzolai, A. Henrion, G. J. Martyna, C. R. M. Grovenor, J. Crain, B. W. Hoogenboom, A. Watts and M. G. Ryadnov, Chemical Science, 2017, 8, 1105-1115. 
